\title{
EVIDENCE SUGGESTING RENAL TUBULAR EXCRETION OF PO- TASSIUM IN MAN DURING RECOVERY FROM ACUTE RENAL INSUFFICIENCY ${ }^{1}$
}

\author{
By JONAS H. SIROTA ${ }^{2}$ AND IRVING G. KROOP 3 WITH THE TECHNICAL ASSISTANCE OF \\ HATTIE WARMBRAND
}

\begin{abstract}
(From the Departments of Medicine and Pediatrics and the Cardiovascular Research Group, The Mount Sinai Hospital, New York, N. Y.)
\end{abstract}

(Submitted for publication April 27, 1951; accepted July 30, 1951)

In 1942 Winkler and Smith (1), studying the simultaneous renal clearances of exogenous creatinine and potassium in dogs following the injection of potassium salts, concluded that potassium is normally filtered at the glomerulus and subjected to a variable degree of tubular reabsorption. The highest potassium/creatinine clearance ratio obtained by these authors was 0.40 . In 1948 Berliner and Kennedy (2), and Mudge, Foulks and Gilman (3) independently and simultaneously published convincing evidence for active renal tubular excretion ${ }^{4}$ of potassium in the dog. The former authors obtained potassium/creatinine clearance ratios as high as 1.33 in trained dogs receiving oral potassium chloride for one week before the experiment, and hypertonic solutions of this substance intravenously during the experiment. The latter investigators obtained potassium/creatinine clearance ratios as high as 1.39 in anesthetized dogs receiving intravenous potassium chloride during urea-induced osmotic diuresis. McCance and Widdowson (4) in 1937 were the first to suggest the possibility of tubular excretion of potassium in man. They observed an isolated potassium/inulin clearance ratio of 1.24 in a man suffering from acute alkalosis at a time when his inulin clearance was depressed to $9.3 \mathrm{ml} . / \mathrm{min}$. In $1943 \mathrm{Keith}$, King and Osterberg (5) stated that they observed

1 This study was supported in part by a grant from The American Heart Association.

2 Sarah Welt Fellow in Medicine.

8 Dazian and Sarah Welt Fellow in Medicine. Present address: Jewish Sanitarium and Hospital for Chronic Disease, Brooklyn, New York.

4 The term "tubular excretion," rather than "tubular secretion," is used advisedly at the suggestion of Dr. Stanley E. Bradley, since the available evidence indicates that the mechanism may be one of ion exchange, akin to the processes of acid and ammonia production by the distal tubule, rather than the processes associated with $\mathrm{PAH}$, diodrast and PSP secretion by the proximal tubule. a potassium/inulin clearance ratio greater than unity in a subject with severe renal insufficiency. No details are given by these authors. Leaf and Camara (6), using 24-hour endogenous "creatinine" clearances as a measure of glomerular filtration rate, obtained potassium/endogenous "creatinine" ratios ranging from 1.21 to 2.07 in four subjects with severe chronic renal insufficiency. Nickel and Bradley (7) have confirmed these observations in chronic renal insufficiency by obtaining potassium/inulin clearance ratios significantly greater than unity.

Berliner (8) suggests that potassium is normally excreted by the triple mechanisms of filtration, tubular reabsorption and tubular excretion. Since the filtered load of potassium is usually much greater than that excreted in the urine it is apparent that demonstration of tubular excretion of this ion in man is dependent upon means for maximally inhibiting tubular reabsorption of potassium by means of osmotic diuresis, as in the dog experiments of Mudge, Foulks and Gilman; by saturating the organism with potassium, as in the dog experiments of Berliner and Kennedy; or by producing a marked reduction of the filtered potassium load. Since the first and second of these methods are too drastic for man, one is necessarily limited to the study of pathologically induced depressions of filtered potassium loads. It occurred to us that the recovery phase of acute renal insufficiency in man would lend itself to such a study, as previously published data (9) indicate that markedly reduced filtration loads may be present at a time when tubular functional integrity is returning. Analysis of our electrolyte and clearance data in five cases of acute renal insufficiency studied by us does in fact strongly suggest that tubular excretion of potassium may occur during the recovery phase. 


\section{METHODS}

Simultaneous daily 24-hour renal clearances of endogenous "creatinine" and potassium were determined in five patients recovering from the oliguric phase of acute renal insufficiency caused by carbon tetrachloride poisoning in four and sulfonamide intoxication in one. The clinical details of these cases will be described elsewhere. Simultaneous acute renal clearances of inulin and endogenous "creatinine" were performed at random intervals.

Daily plasma analyses for potassium and "creatinine" were performed upon fasting morning blood specimens drawn without stasis into heparinized tubes and immediately centrifuged. Twenty-four hour urines were collected in bottles containing $3 \mathrm{ml}$. of toluol and were analyzed for potassium and "creatinine" content. When the urine volumes were under $500 \mathrm{ml}$./day the patients were catheterized at the end of each 24-hour period to insure complete bladder emptying. The remainder of the 24-hour urines were collected by spontaneous voiding. Indwelling catheters were not used. Bilateral ureteral catheterization was performed on one subject (L. P.) on the day of admission. For the acute inulin clearance determinations indwelling urethral catheters were used and the bladders were emptied by means of water and air washouts. The above constituted the only instances of urological manipulation. Representative plasma concentrations for calculating the 24-hour clearances of potassium and endogenous "creatinine" were obtained by averaging the values of two successive mornings. This average value was then applied to the urine collected during the intervening 24 hours. Inulin clearances were performed according to the standardized techniques of Smith, Goldring and Chasis (10).

Initially the patients' diets consisted of sweetened fluids of low potassium content in volumes calculated to maintain them in slightly negative fluid balance. With the onset of diuresis, they were placed on a low protein, high carbohydrate, low sodium (5 to 10 meq./day), constant potassium (40-50 meq./day) diet as tolerated. When the diuretic phase was well established fluids and salt were added ad lib. Regular ward diets were given when evidences of nitrogen retention were minimal.

Inulin was determined by a modification of Harrison's method as described by Goldring and Chasis (11). "Creatinine" was determined in plasma and urine by means of the Bonsnes and Taussky method (12). The plasma proteins for this determination were precipitated by a modification of the Folin-Wu method (13), which utilizes onehalf the amount of tungstate usually recommended. When employed with the Bonsnes-Taussky modification of the Jaffe reaction this protein precipitation method yields better plasma recoveries of added creatinine from concentrated precipitates ( 1 to 4 precipitation dilution) than the standard Folin-Wu technique. ${ }^{5}$ The Coleman Jr. Spec-

$\checkmark$ With elevated concentrations of plasma creatinine concentrated precipitates are not necessary. Precipitation dilutions of 1 to 6 or higher may be employed with plasma creatinine concentrations about $2.0 \mathrm{mgm} . / 100 \mathrm{ml}$. For trophotometer was used for all colorimetric determinations. Potassium analyses were performed with the PerkinElmer internal standard flame photometer Model 52A in accordance with the techniques recommended in the Perkin-Elmer instruction manual. A standard potassium curve was determined with each series of determinations and the closest standard point was checked following each unknown determination. Lithium, at a concentration of 20 meq. $/ \mathrm{L}$., was used as the internal standard. Utilizing this technique plasma concentrations in normal subjects ranged from 3.7 to 5.0 meq./L. Recoveries of added potassium to plasma and urine ranged from 97.0 to 102 per cent.

\section{RESULTS}

Daily urine flows (V), 24-hour endogenous "creatinine" clearances $\left(\mathrm{C}_{\mathrm{CR}}\right)$, plasma potassium concentration $\left(P_{K}\right)$, 24-hour urine potassium output $\left(U_{\mathbf{K}}\right)$, potassium/endogenous "creatinine" clearance ratios $\left(\mathrm{C}_{\mathbf{K}} / \mathrm{C}_{\mathbf{C R}}\right)$, occasional endogenous "creatinine"/inulin clearance ratios $\left(\mathrm{C}_{\mathrm{OR}} / \mathrm{C}_{\mathrm{IN}}\right)$, plasma creatinine concentrations $\left(\mathrm{P}_{\mathrm{OR}}\right)$, and plasma urea nitrogen concentrations $\left(P_{\mathbb{V}}\right)$ are presented in Table $I$ for all five subjects. It is evident that during the early recovery phase four of the subjects exhibited 24-hour potassium clearances of greater magnitude than simultaneous endogenous "creatinine" clearances $\left(\mathrm{C}_{\mathrm{K}} / \mathrm{C}_{\mathrm{KR}}>1.00\right)$. This phenomenon occurred in the four patients with carbon tetrachloride poisoning and was absent in the one subject with sulfonamide intoxication (L. P.). In subject F. Mc. a $\mathrm{C}_{\mathrm{K}} / \mathrm{C}_{\mathrm{OR}}$ ratio of 2.20 was present on the first day of increased urine volume. True diuresis did not begin until the next day. This ratio continued to be greater than 1.00 for seven additional days, until a $C_{C R}$ of 12.1 $\mathrm{ml}$./min. was attained. In subject $H$. Z. the $\mathrm{C}_{\mathrm{K}}$ / $\mathrm{C}_{\mathrm{CR}}$ ratio was 1.36 on the first day of observation,

these more dilute precipitates the standard Folin-Wu tungstic acid method may be used, as recoveries by both methods are equally good at these higher dilutions.

The use of $1 / 3$ molar tungstate with $2 / 3$ molar sulfuric acid as advocated by Brod and Sirota (13) for low precipitation dilutions results in an acid filtrate. The alkaline picrate used to develop the Jaffe color must therefore be sufficiently alkaline to obviate errors which may be introduced by this acid filtrate. The Bonsnes-Taussky modification of the Jaffe reaction was found satisfactory. No differences were observed in the final Jaffe colors developed when this method was used with both the standard (neutral filtrate) and modified (acid filtrate) protein precipitation methods at precipitation dilutions above 1 to 6 . 


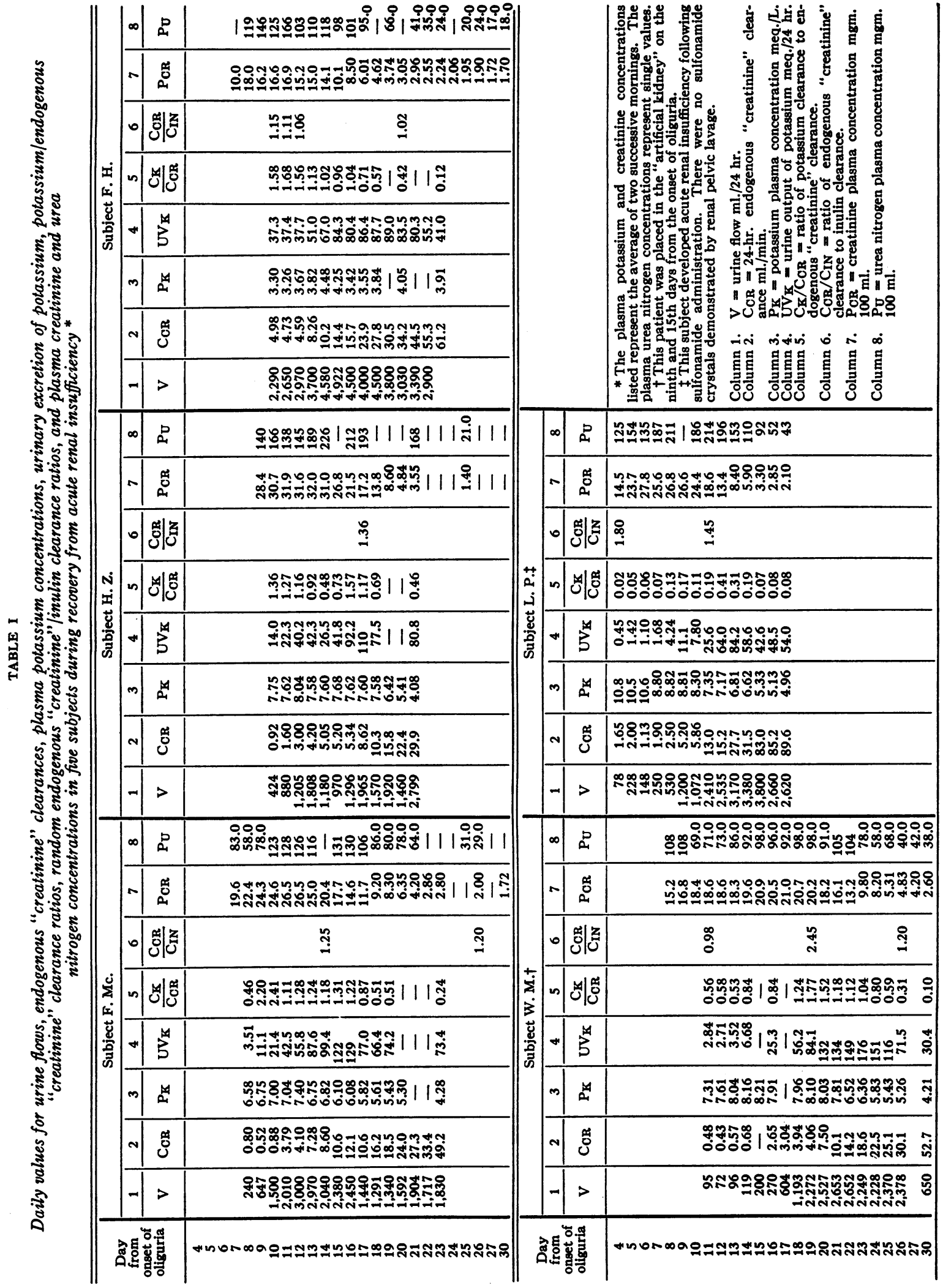




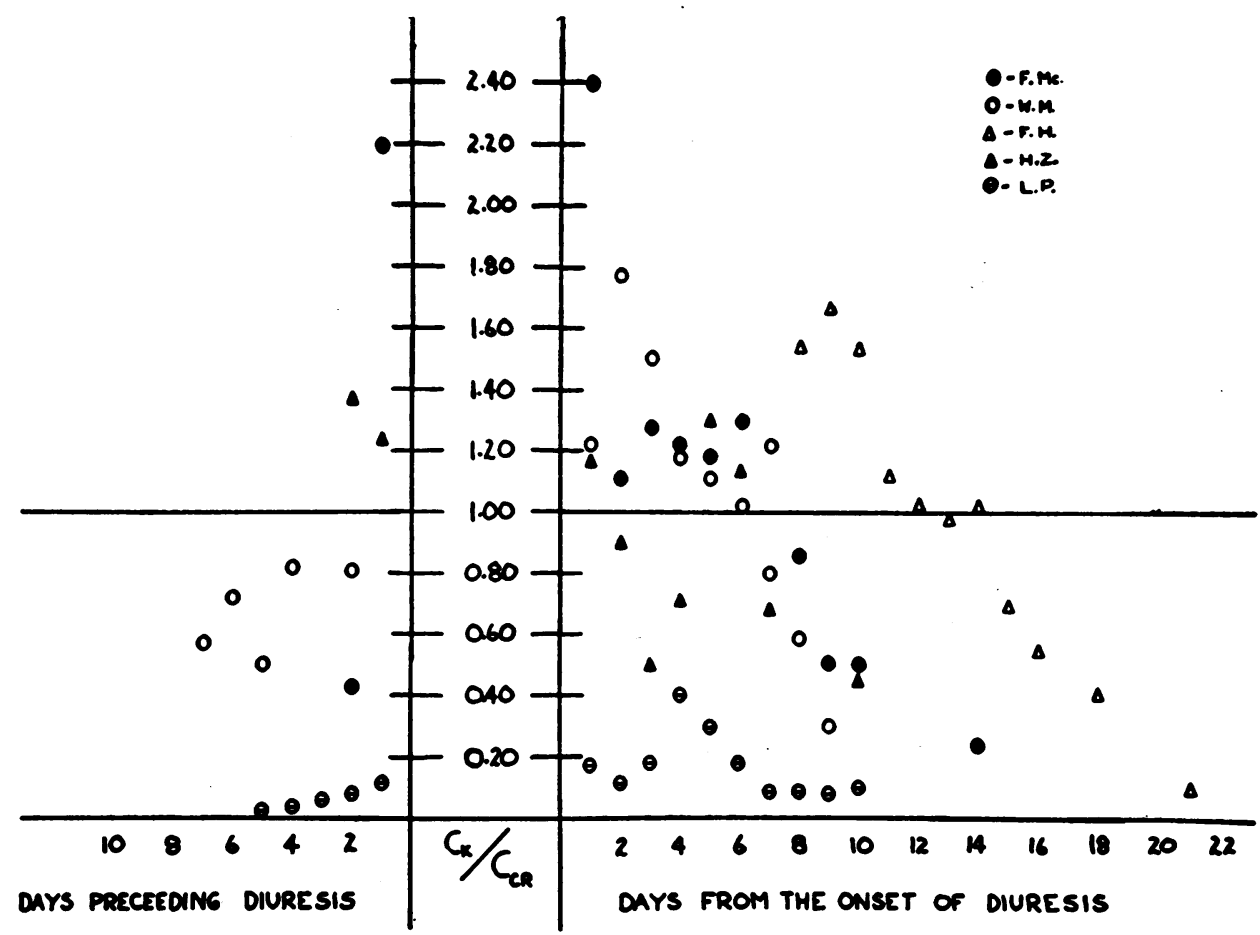

Fig. 1. Simultaneous 24-Hour Potassium/Endogenous "Creatinine" Clearance Ratios Present in Frve Subjects with Acute Renal Insufficiency Preceding and Following the ONSET OF DIURESIS

while still oliguric. For the next seven days it ranged between 0.48 and 1.33 , being greater than 1.00 for four of those days and ceasing to be so when $\mathrm{C}_{\mathrm{OR}}$ reached $10.3 \mathrm{ml} . / \mathrm{min}$. Subject $\mathrm{F}$. $\mathrm{H}$. was not oliguric when first observed. ${ }^{\circ}$ The $C_{K}$ / $\mathrm{C}_{\mathrm{OR}}$ ratio was significantly greater than 1.00 during the first four days of observation (1.13 to 1.68) and dropped to levels significantly less than 1.00 when $\mathrm{C}_{\mathbf{C R}}$ reached $23.9 \mathrm{ml}$./min. Subject W. M. had severe oliguria for 17 days. $A C_{K} / C_{C R}$ ratio of 1.24 was present on the first day of diuresis. This ratio remained significantly greater than 1.00 for five days. At a $\mathrm{C}_{\mathrm{OR}}$ of $22.5 \mathrm{ml}$./min. the $\mathrm{C}_{\mathrm{K}} /$ $\mathrm{C}_{\mathrm{CR}}$ ratio became less than 1.00 . Subject L. P. (sulfonamide poisoning) had $\mathrm{C}_{\mathrm{K}} / \mathrm{C}_{\mathrm{CR}}$ ratios well under 1.00 throughout the observed recovery period. The highest ratio attained was 0.41 , on the fourth day of diuresis, at a time when $C_{0 R}$ was $15.2 \mathrm{ml} . / \mathrm{min}$. In all subjects random inulin clear-

6 There was a two-day period of questionable oliguria in this patient following exposure to carbon tetrachloride. When first seen, 10 days after exposure, his blood urea nitrogen was $146 \mathrm{mgm} . / 100 \mathrm{ml}$. and his plasma "creatinine" concentration was $16 \mathrm{mgm} . / 100 \mathrm{ml}$. in spite of urine flows of over $2,000 \mathrm{ml}$./day. ances $\left(C_{I N}\right)$ were either similar to or significantly lower than simultaneous endogenous "creatinine" clearances. At no time was $\mathrm{C}_{\mathrm{IN}}$ significantly higher, suggesting that the 24-hour $C_{C R}$ is at least at the level of $\mathrm{C}_{\mathrm{IN}}$, and probably significantly higher most of the time during the early recovery phase. Figure 1 presents all the $C_{K} / C_{C R}$ ratios plotted against days preceding and following the onset of diuresis. A total of $25 \mathrm{C}_{\mathrm{K}} / \mathrm{C}_{\mathrm{CR}}$ ratios greater than 1.00 were observed during the time interval representing the period from two days before the onset of diuresis ( $\mathrm{V}>900 \mathrm{ml}$./day) to 14 days after. The three observed before the onset of diuresis were during increasing urine flows, which had not yet attained the arbitrarily chosen value of $900 \mathrm{ml}$./day.

The plasma potassium concentrations were elevated in all subjects except $F$. $H$. There appeared to be no correlation between the plasma potassium level and the $C_{K} / C_{C R}$ ratios. Thus, subject $L$. $P$. with a plasma concentration of $8.81 \mathrm{meq} . / \mathrm{L}$. at the onset of diuresis maintained $\mathrm{C}_{\mathrm{K}} / \mathrm{C}_{\mathrm{CR}}$ ratios well under 1.00 ; whereas $\mathrm{F}$. H. with a plasma potassium concentration of 3.30 meq./L. revealed a 
$\mathrm{C}_{\mathrm{K}} / \mathrm{C}_{\mathrm{OR}}$ ratio of 1.58 on the first day of observation. Also, there appeared to be no correlation between $\mathrm{C}_{\mathrm{K}} / \mathrm{C}_{\mathrm{CR}}$ ratios and the oral intake of potassium.

\section{DISCUSSION}

In order to prove tubular excretion of potassium it must be demonstrated that the quantity of this substance excreted in the urine over a given time interval is greater than that filtered through the glomeruli over the same time interval. This latter determination, referred to as the filtered load, is a product of the glomerular filtration rate and the plasma concentration. ${ }^{7}$ The accuracy of measuring the filtered load of potassium is primarily dependent upon measurement of glomerular filtration rate. The interpretation of both endogenous "creatinine" and inulin clearance data as indicators of glomerular activity during severe renal insuffciency is open to question. There is evidence to suggest that tubular back-diffusion of the glomerular filtrate or some of the filtrate solutes may occur following severe renal injuries (14-17). Under such circumstances the renal clearances of endogenous "creatinine" and inulin may be considerably lower than the true glomerular filtration rate, and hence the filtered potassium load calculated from these data may be significantly lower than the true values. In spite of this cogent objection to our data, we feel that they strongly suggest the occurrence of tubular excretion of potassium for the following reasons:

1. Although the product of $\mathrm{C}_{\mathrm{IN}}$ or $\mathrm{C}_{\mathrm{CR}} \times \mathrm{P}_{\mathrm{K}}$ may be meaningless under these circumstances because of back-diffusion, the ratio $\mathrm{C}_{\mathrm{K}} / \mathrm{C}_{\mathrm{CR}}$ greater than 1.00 is not. This latter expression simply means that more of the plasma reaching the kidney is being virtually cleared of potassium than of "creatinine." Unless one assumes that the glomeruli have become more permeable to potassium than to "creatinine" or that "creatinine" is back-

\footnotetext{
7 In order to calculate the amount of potassium filtered from the product $G F R \times P_{K}$, one should for greatest accuracy take into account the correction factors for plasma water and the Donnan equilibrium. However, since these two factors are of approximately the same magnitude and apply corrections in opposite directions they may be ignored, since our best methods for measuring GFR have inherent errors of $\mathbf{5}$ per cent or more.
}

diffusing across damaged tubule cells at a more rapid rate than potassium, tubular excretion of potassium must be postulated. Since $\mathrm{C}_{\mathrm{IN}}$ has been shown to be equal to or less than $C_{\mathrm{CR}}, \mathrm{C}_{\mathrm{K}} / \mathrm{C}_{\mathrm{IN}}$ must be equal to or greater than $\mathrm{C}_{\mathrm{K}} / \mathrm{C}_{\mathrm{CR}}$. The probability of potassium back-diffusing at a slower rate than inulin, with a molecular weight of 5,000 , appears slight.

2. If one were to assume that $\mathrm{C}_{\mathrm{K}} / \mathrm{C}_{\mathrm{CR}}$ ratios greater than 1.00 were in some way merely the result of severe architectural derangement of the nephrons it would be difficult to explain why this phenomenon occurred with the onset of diuresis in subject W. M., a time thought to be associated with early reestablishment of tubular integrity, rather than during the oliguric period, the time of severest morphological derangement $(9,18){ }^{8}$ Also, this assumption would fail to explain the complete absence of $C_{K} / C_{O R}$ ratios greater than 1.00 in subject L. P. with eight days of severe oliguria caused by sulfonamide intoxication in which severe tubular disorganization occurs with a severity equal to other causes of "lower nephron nephrosis" (18).

The disappearance of $\mathrm{C}_{\mathrm{K}} / \mathrm{C}_{\mathrm{CR}}$ ratios greater than 1.00 with rising $C_{C R}$ suggests that the tubular excretion of potassium does not necessarily cease, but might become masked by larger filtered potassium loads available for reabsorption and tubular rejection. We have no explanation for the failure to observe $C_{\mathrm{K}} / \mathrm{C}_{\mathrm{CR}}$ ratios greater than 1.00 in the one case of sulfonamide intoxication. The nature of the cellular injuries in this case may have been such as to destroy the mechanism responsible for tubular excretion of potassium; or perhaps this phenomenon may indeed be a peculiarity of carbon tetrachloride poisoning. Further observations on subjects with acute renal insufficiency of varied etiology are required to determine this point. However, similar observations have been made which suggest tubular excretion of potassium during acute experimental reductions

8 The onset of diuresis following acute renal insufficiency in the authors' opinion represents reestablishment of tubular functional integrity with respect to the passive back-diffusion of water, as the urine output may increase many fold with little or no change in $\mathrm{C}_{\mathrm{OR}}$ or $\mathrm{C}_{\mathrm{IN}}$. This stage correlates morphologically with regeneration of tubule cells. 
of filtered potassium loads. Thus Farber, Alexander and Earle have demonstrated transient $\mathrm{C}_{\mathrm{K}} / \mathrm{C}_{\mathrm{CR}}$ ratios significantly greater than 1.00 following acute experimental anuria in dogs (19), and Breed and Baxter have demonstrated $\mathrm{C}_{\mathrm{K}} / \mathrm{C}_{\mathrm{IN}}$ ratios greater than 1.00 during shock in one human subject (20).

It is probable that some of the potassium found in the urine represents that liberated as a result of renal parenchymal destruction. The quantity of potassium contributed to the urine by such tissue destruction is difficult to assess. However, as Lucké (18) has shown, at the time when diuresis usually occurs, regenerative processes rather than destructive ones are manifest. It would thus be difficult to explain excess potassium excretion on the basis of tissue destruction as late as the 14th day of diuresis. Since urological manipulation was minimal during the periods of study mechanical tissue trauma cannot be implicated as a spurious source of potassium in the urine.

According to Berliner (8) the most potent stimulus for increasing tubular excretion of potassium appears to be high intracellular potassium concentrations. This remarkable tubular adaptability of even the severely damaged kidneys of terminal glomerulonephritis and acute renal insufficiency to rid the organism of excess potassium in spite of markedly reduced glomerular function explains the usual absence of significant hyperkalemia in these conditions so long as urine flow is maintained above the oliguric level.

\section{CONCLUSIONS}

1. Simultaneous 24-hour clearances of endogenous "creatinine" and potassium were determined daily in five subjects with acute renal insufficiency resulting from carbon tetrachloride poisoning in four and sulfonamide poisoning in one. Potassium/endogenous "creatinine" clearance $\left(\mathrm{C}_{\mathrm{K}} / \mathrm{C}_{\mathrm{CR}}\right)$ ratios significantly greater than 1.00 were found in the four patients poisoned by carbon tetrachloride during early recovery from oliguria, suggesting the occurrence of renal tubular excretion of potassium.

2. A total of $25 \mathrm{C}_{\mathrm{K}} / \mathrm{C}_{\mathrm{OR}}$ ratios greater than unity were observed with a range of 1.02 to 2.41 and a mean of 1.36. Potassium clearances in excess of simultaneous endogenous "creatinine" clearances were observed as long as the 14 th day from the onset of diuresis.

3. The highest $\mathrm{C}_{\mathrm{CR}}$ at which the $\mathrm{C}_{\mathrm{K}} / \mathrm{C}_{\mathbf{C R}}$ ratio was greater than 1.00 was $18.6 \mathrm{ml} . / \mathrm{min}$. It is suggested that in order to demonstrate the presence of tubular excretion of potassium in man, one must seek this phenomenon in the presence of low filtration loads of potassium.

4. Random simultaneous endogenous "creatinine" and inulin clearances during the period of study in these subjects revealed the $C_{\mathbf{C R}}$ values to be equal to or greater than the $\mathrm{C}_{\mathrm{IN}}$ values; never significantly lower.

\section{ACKNOWLEDGMENT}

We are indebted to Dr. Irving Graef for allowing us to study patient W. M., who was admitted to The Mount Sinai Hospital for the "artificial kidney."

\section{REFERENCES}

1. Winkler, A. W., and Smith, P. K., Renal excretion of potassium salts. Am. J. Physiol., 1942, 138, 94.

2. Berliner, R. W., and Kennedy, R. J., Jr., Renal tubular secretion of potassium in the normal dog. Proc. Soc. Exper. Biol. \& Med., 1948, 67, 542.

3. Mudge, G. H., Foulks, J., and Gilman, A., The renal excretion of potassium. Proc. Soc. Exper. Biol. \& Med., 1948, 67, 545.

4. McCance, R. A., and Widdowson, E. M., Alkalosis with disordered kidney functions. Lancet, 1937, 2, 247.

5. Keith, N. M., King, H. E., and Osterberg, A. E., Serum concentration and renal clearance of potassium in severe renal insufficiency in man. Arch. Int. Med., 1943, 71, 675.

6. Leaf, A., and Camara, A. A., Renal tubular secretion of potassium in man. J. Clin. Invest., 1949, $28,1526$.

7. Nickel, J. F., and Bradley, S. E., Personal communication.

8. Berliner, R. W., Renal excretion of water, sodium, chloride, potassium, calcium, and magnesium. Am. J. Med., 1950, 9, 541.

9. Sirota, J. H., Carbon tetrachloride poisoning in man. I. The mechanisms of renal failure and recovery. J. Clin. Invest., 1949, 28, 1412.

10. Smith, H. W., Goldring, W., and Chasis, H., The measurement of the tubular excretory mass, effective blood flow and filtration rate in the normal human kidney. J. Clin. Invest., 1938, 17, 263.

11. Goldring, W., and Chasis, H., Hypertension and $\mathrm{Hy}$ pertensive Disease. The Commonwealth Fund, New York, 1944. 
12. Bonsnes, R. W., and Taussky, H. H., On the colorimetric determination of creatinine by the Jaffé reaction. J. Biol. Chem., 1945, 158, 581.

13. Brod, J., and Sirota, J. H., The renal clearance of endogenous "creatinine" in man. J. Clin. Invest., 1948, 27, 645.

14. Richards, A. N., Direct observations of change in function of the renal tubule caused by certain poisons. Tr. A. Am. Physicians, 1929, 44, 64.

15. Bobey, M. E., Longley, L. P., Dickes, R., Price, J. W., and Hayman, J. M., Jr., The effect of uranium poisoning on plasma diodrast clearance and renal plasma flow in the dog. Am. J. Physiol., 1943, 139, 155.

16. Richards, A. N., Westfall, B. B., and Bott, P. A.,
Inulin and creatinine clearances in dogs, with notes on some late effects of uranium poisoning. J. Biol. Chem., 1936, 116, 749.

17. Phillips, R. A., and Hamilton, P. B., Effect of 20,60 and 120 minutes of renal ischemia on glomerular and tubular function. Am. J. Physiol., 1948, 152, 523.

18. Lucké, B., Lower nephron nephrosis (the renal lesions of the crush syndrome, of burns, transfusions, and other conditions affecting the lower segments of the nephrons). Mil. Surgeon, 1946, 99, 371.

19. Farber, S. J., Alexander, J. D., and Earle, D. P., Personal communication.

20. Breed, E. S., and Baxter, C. F., Personal communication. 